\title{
Protocol of supra-visceral aortic ischemic preconditioning for open surgical repair of thoracoabdominal aortic aneurysm
}

\section{The EPICATA study (Evaluation of the Efficacy of Ischemic PreConditioning on morbidity and mortality in open ThoracoAbdominal Aortic surgery)}

\author{
Mickael Palmier ${ }^{1}$, Mickael Bubenheim², Laurent Chiche ${ }^{3}$, Xavier Chaufour ${ }^{4}$, Fabien Koskas ${ }^{3}$, Elie Fadel ${ }^{5}$, \\ Pierre Edouard Magnan ${ }^{6}$, Eric Ducasse ${ }^{7}$, Nabil Chakfe $^{8}$, Eric Steinmetz ${ }^{9}$, Marie Melody Dusseaux $^{10}$, \\ Jean Baptiste Ricco ${ }^{11}$ and Didier Plissonnier ${ }^{1 *}$
}

\begin{abstract}
Background: Open surgical repair (OSR) for thoracoabdominal aortic aneurysms (TAA) is associated with a high pulmonary and renal morbidity rate. Ischemic preconditioning (IPC) is a mechanism of protection against the deleterious effects of ischemia-reperfusion. To our knowledge IPC has never been tested during OSR for TAA.

Methods: The primary objective of the study is to evaluate the efficacy of IPC during OSR for TAA with respect to acute kidney injury (AKI) according to KDIGO and pneumonia/prolonged ventilation-time during the first 8 postoperative days. The secondary objectives are to compare both arms with respect to cardiac complications within $48 \mathrm{~h}$, renal and pulmonary complications within 21 days and mortality at 60 days.

To assess the efficacy of IPC with respect to pulmonary and renal morbidity, a cox model for competing risks will be used. Assuming that the event occurs among 36\% of the patients when no IPC is performed, the allocation of 55 patients to each arm should allow detecting a hazard ratio of at least 2.75 with a power of $80 \%$ when admitting $5 \%$ for an error of first kind. This means that 110 patients, enrolled in this multicenter study, may be randomised within 36 months of the first randomization.

Randomization will be performed to allocate patients either to surgery with preconditioning before aortic cross clamping (Arm 1) or to surgery without preconditioning before aortic cross clamping (Arm 2). Randomization takes place during the intervention after intravenous injection of heparin, or after the start of femoral assistance. The procedure for IPC will be a supra-visceral thoracic aortic cross clamping for 5 min followed by an unclamping period of $5 \mathrm{~min}$. This procedure will be repeated twice before starting thoracic aortic cross (Continued on next page)
\end{abstract}

\footnotetext{
* Correspondence: didier.plissonnier@gmail.com

'Department of vascular surgery and Inserm U1096, Rouen University Hospital, 1 rue de Germont, 76031 Rouen Cedex, France

Full list of author information is available at the end of the article
}

(c) The Author(s). 2020 Open Access This article is licensed under a Creative Commons Attribution 4.0 International License, which permits use, sharing, adaptation, distribution and reproduction in any medium or format, as long as you give appropriate credit to the original author(s) and the source, provide a link to the Creative Commons licence, and indicate if changes were made. The images or other third party material in this article are included in the article's Creative Commons licence, unless indicated otherwise in a credit line to the material. If material is not included in the article's Creative Commons licence and your intended use is not permitted by statutory regulation or exceeds the permitted use, you will need to obtain permission directly from the copyright holder. To view a copy of this licence, visit http://creativecommons.org/licenses/by/4.0/. The Creative Commons Public Domain Dedication waiver (http://creativecommons.org/publicdomain/zero/1.0/) applies to the data made available in this article, unless otherwise stated in a credit line to the data. 
(Continued from previous page)

clamping needed to perform surgery.

Conclusions: Our hypothesis is that ischemic preconditioning could reduce clinical morbidity and the incidence of lung damage associated with supra-visceral aortic clamping.

Trial registration: EPICATAStudy registered in ClinicalTrial.gov / number: NCT03718312 on Oct.24.2018 URL number

Keywords: Thoracoabdominal aortic aneurysm, Preconditioning, Pulmonary and renal morbidity

\section{Background}

Mortality rate after OSR for TAA is estimated between 4 and $15 \%[1,2]$. Pulmonary and renal complications can reach up to $50 \%$ and more $[3,4]$. Compared to OSR for infrarenal abdominal aortic aneurysm (AAA), TAA requires repair of the visceral arteries with a supravisceral aortic cross-clamping often greater than $30 \mathrm{~min}$. Following OSR for TAA, Serious lung damage reached $60 \%$ in large series $[3,5]$ and 40 to $50 \%$ in recent publications [6]. The hypothesis of a causal link between visceral ischemia and the occurrence of organ failure and particularly lung damage is the main focus of this study. Mesenteric ischemia reperfusion caused by aortic cross clamping above the celiac trunk and the superior mesenteric artery is involved in the onset of a systemic inflammatory response (SIRS) leading to multiple organ failure (MOF) [7-10]. Interestingly, distal perfusion of the aorta by a shunt reduces the onset of paraplegia, but increases the production of cytokines and complications associated with the inflammatory response [11, 12].

The main actors of the inflammatory response to ischemia-reperfusion are free radicals' oxygen, polymorphonuclear neutrophil cells (PMN) and cytokines, all at the origin of the deleterious complications [1315]. In particular, activity of neutrophils could be a key factor in remote lung injury $[16,17]$.

Beside remote lung injury, renal damage can be mainly attributed to direct effect of cross aortic clamping during TAA. Severe acute renal failure reaches $25 \%$ with dialysis required in $17 \%$ of patients [6] with an increased risk of death [18]. Wynn et al. reported that renal failure as defined in the RIFLE classification [19] was not associated with increased mortality [20]. According to Tshomba et al. [21] acute renal failure is often temporary. But even temporary, it is possible that acute renal failure observed in this context may later favour the onset of chronic renal failure [22].

IPC applied to OSR for AAA was reported to reduce myocardial and renal damage [23]. But this result has been debated and other studies have reported negative results with IPC during AAA OSR [24] or peripheral vascular surgery [25]. IPC has been shown to improve lung function measured by blood gases and mesenteric aggression measured by lactate blood level [26]. Finally, a recent meta-analysis of 9 randomized trials, focused on the effects of remote IPC in patients operated for AAA, through an open or an endovascular approach, failed to report any beneficial effect on mortality, myocardial ischemia and renal impairment [27]. But these series were carried out during OSR of infrarenal AAA where the visceral arteries were not involved in aortic reconstruction and by that ischemia reperfusion damage [24, 25]. In these conditions, the protective effects of IPC appear difficult to evaluate [27-29]. In the same way, the CRIPES studying EVAR, which required no aortic clamping, did not show any protective effect of IPC on myocardial function [30]. On the contrary, a recent meta-analysis showed that IPC performed by clamping the thoracic aorta while performing coronary bypass, reduced the duration of postoperative artificial ventilation and myocardial ischemia [31].

\section{Rationale of the study}

Our hypothesis is the existence of a causal relationship between visceral ischemia and remote organ failure. Visceral aortic cross clamping causes mesenteric and renal cells ischemia reperfusion injury leading to an intense and systemic inflammatory activity which could affect remote organs.

IPC may be a useful tool for endogenous protection against the deleterious effects of ischemia-reperfusion has been already demonstrated in myocardial ischemia [32], liver and kidney ischemia [33], but IPC for direct OSR of TAA requiring supravisceral aortic cross clamping has never been tested.

\section{Methods/design}

\section{Trial objective}

The primary objective of the study is to evaluate the efficacy of IPC applied directly to the supravisceral aorta during OSR for TAA with respect to acute kidney injury (AKI) according to KDIGO and pneumonia/prolonged ventilation-time during the 8-day postoperative period.

The secondary objectives are to compare both arms with respect to cardiac complications within $48 \mathrm{~h}$, renal and pulmonary complications within 21 days and mortality at 60 days. 


\section{Trial design}

EPICATA is a randomized, open, multicentric national French study, the essential aspects of which have been summarized on a flowchart (Fig. 1).

\section{Primay endpoint}

The primary endpoint is the occurrence of a first pulmonary or renal complication during the 8-day postoperative period.

Pulmonary complications are defined as:

- The necessity of prolonged artificial ventilation, i.e. no extubation before the 48-h following the surgery

- The need for a new ventilation (invasive or noninvasive) within 48-h following initial extubation
- The occurrence of a moderate or severe acute respiratory failure, according to the Berlin definition [34].

Renal complication is defined as the occurrence of an acute kidney failure according to the RIFLE classification [19], as "injury", "failure" or "loss" during the first postoperative week.

\section{Secondary endpoints}

The secondary endpoints are:

- Need for new ventilation (invasive or noninvasive) $48 \mathrm{~h}$ after the arrest of initial ventilation, during a 21-day postoperative period.

- Renal failure occurring during a 21-day postoperative period according to the RIFLE classification

Thoracoabdominal Aortic Aneurysms assessed for Open Surgery
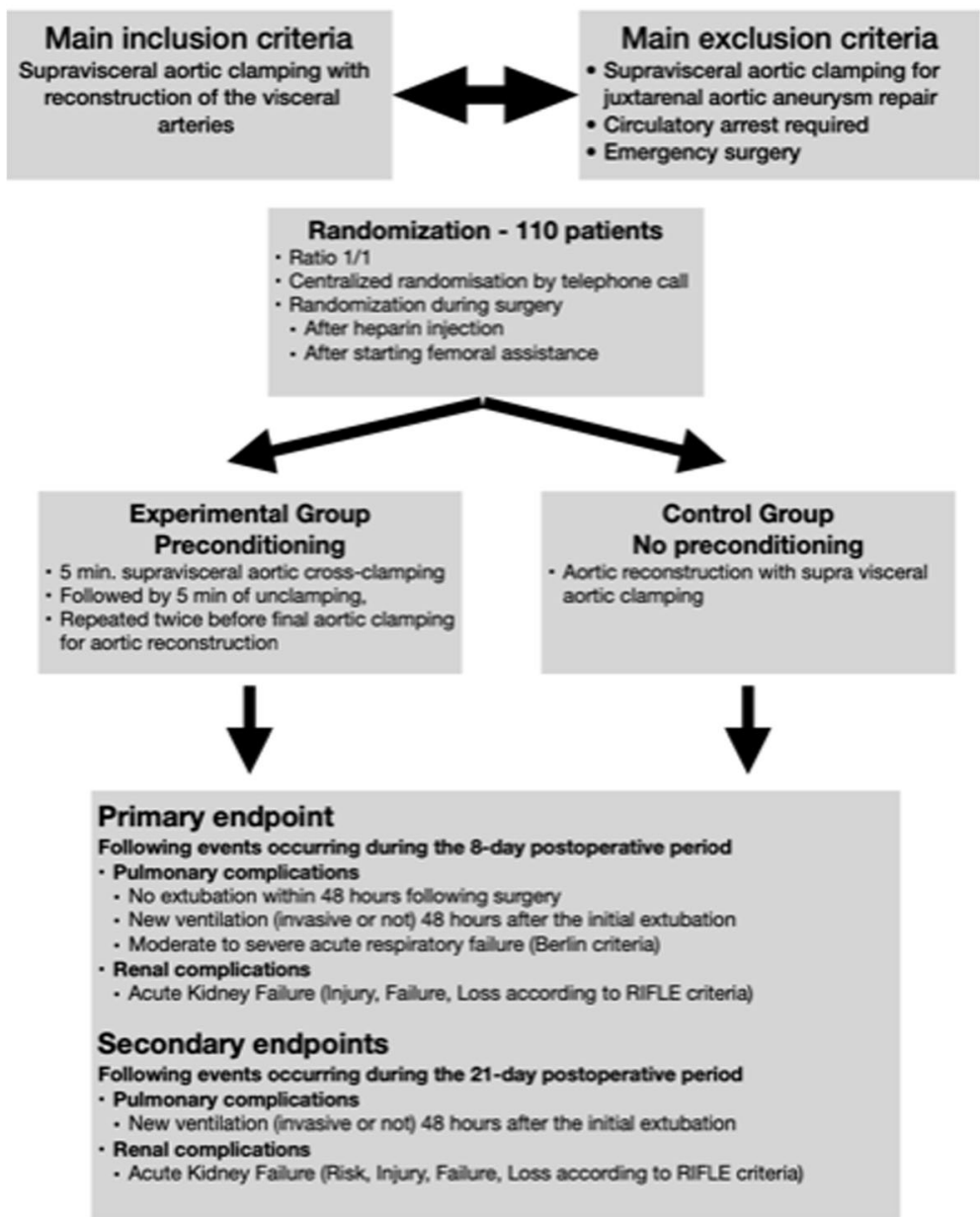

Fig. 1 Study protocol flow chart 
- Cardiac morbidity: daily serum troponin $>1.5$ normal level (specific in each center) within the 48-h postoperative period.

- Cellular and tissue visceral impairment: daily serum D-lactate during the first 8-day postoperative period.

- Mortality at 60 days

This study is randomized in two arms on the day of surgery by drawing lots

Arm 1: patients with aortic clamping with preconditioning

Arm 2: patients with aortic clamping without preconditioning

\section{Eligibility}

\section{Inclusion criteria}

- Patients of at least 18 years

- Signed written informed consent

- Patients with thoracoabdominal aortic aneurysms (TAAA), type 1 to 5 according to Crawford/Safi classification, scheduled for open surgery

- Patients with AAA requiring supra-visceral aortic cross clamping and reconstruction of the visceral arteries

- Patients with TAAA with or without distal femoral perfusion assistance

- Patients with degenerative TAAA or post aortic dissection TAAA

- Patients having read and understood the information letter and signed the Informed Consent Form

- Patients affiliated to, or beneficiary of a social security coverage.

\section{Exclusion criteria}

- Patients with AAA which require supra-visceral aortic cross clamping but not reconstruction of the visceral arteries (supra-visceral aortic cross clamping for juxta renal aortic aneurysms)

- Patients with TAAA which require a circulatory arrest (aortic aneurysms which affect all the descendant thoracic aorta and the aortic arch)

- Patients requiring emergency surgery

- Patients receiving treatments that may interact with preconditioning such as nicorandil or oral antidiabetics.

- Pregnant women. Women who are not postmenopausal ( $\geq 12$ months of non-therapyinduced amenorrhea) or not surgically sterile must have a negative serum pregnancy test within 1 week prior to randomization.
- Participation in another interventional clinical trial within 28 days prior to randomization and during the study

- Person deprived of liberty by administrative or judicial decision or placed under judicial protection (guardianship or supervision).

\section{Trial intervention}

\section{Surgical procedure}

Surgical procedures were harmonized between the different centers during a common previous meeting after the protocol edition. The procedure for aortic surgical repair is well established and applied similarly in the different surgical centers. Cerebrospinal fluid drainage will be performed and monitored the operation and for the subsequent 48 to $72 \mathrm{~h}$. Left heart bypass will be used: arterial cannulation will be carried out through the femoral artery and venous cannulation will be placed in the right atrium through the femoral vein. Distal bypass flows will be in range of 1.5 to $21 / \mathrm{mn}$. Operation will be conducted with permissive hypothermia. Repair of the aorta will be driven through the sequential aortic clamping technique. When preoperatively identified, intercostal vessels destined for the spinal cord will be reattached to the aortic graft. Otherwise, all patent intercostal arteries from $\mathrm{T} 8$ to $\mathrm{T} 12$ will be reattached in the main graft. When possible, visceral arteries and the right renal artery will be repaired in a single aortic patch reattached in the main graft. Most of the time, the left renal artery will be repaired separately. Because of the rationale of the study, testing the efficacy of preconditioning for protection against the deleterious effects of ischemiareperfusion, visceral and renal vessels will not be perfused.

Type IV TAAA will be operated without cerebrospinal fluid drainage and without left heart bypass but according the clamp and go technique.

\section{Experimental group}

The experimental group consists of patients receiving open TAAA surgery with direct preconditioning by clamping of the supra-visceral aorta.

Randomization allocation will be given to the surgeon during the procedure after intravenous injection of heparin, or after starting femoral assistance. The IPC will be a supra-visceral thoracic aortic cross clamping of 5 min followed by an unclamping period of $5 \mathrm{~min}$. It will be repeated twice before starting the thoracic aortic cross clamping needed to perform surgery. The level of aortic cross clamping for IPC will be that required for aortic repair whose technique has been described elsewhere [35].

Postoperative follow-up will be the same as for standard OSR for TAAA. The follow-up period will cover the 
duration of hospitalization or will end on the 61st postoperative day in the event of prolongation of hospitalization beyond 60 days.

\section{Control group}

Patients will receive standard OSR for TAAA without preconditioning.

Postoperative follow-up will be the same as for the experimental group.

\section{Follow-up}

The data collected during the intervention and during the postoperative period are presented in Tables 1 and 2 .

\section{Trial setting}

Exclusive involvement of expert centres in aortic surgery with about 150 open aortic surgical procedures per year. The participating University hospitals are Charles Nicolle in Rouen (France), Rangueil in Toulouse (France), La Pitié Salpétrière in Paris, Centre chirurgical Marie Lannelongue in Le Plessis Robinson, La Timone in Marseille (France), Pellegrin in Bordeaux (France), Nouvel Hopital Civil in Strasbourg (France) and Le Bocage in Dijon (France).

\section{Study schedule}

- Enrolment period: 36 months

- Follow-up period: 2 months

- Total duration of the study: 38 months

\section{Screening visit (day - 60 to day - 5 prior to} randomization)

Visit 2 baseline (week 0/Day-1)

The baseline visit occur after the patient has signed the informed consent document. All baseline procedures and tests must be completed prior to randomization:

Table 1 Data collected during surgery

Peroperative data collected
Total duration of intervention (mn)
Duration of aortic clamping ( $\mathrm{mn}$ )
Duration of visceral arteries clamping
(celiac axis, mesenteric artery, renal arteries)
Duration of distal aortic perfusion (femoral assistance) when used
$\mathrm{mL}$ of blood returned by the cell-saver
$\mathrm{mL}$ of blood products transfused
Peroperative urine output
Hemodynamic monitoring points (when available): CI / BP / CF
- before aortic clamping
- during aortic unclamping
Cl Cardiac Index, BP Blood Pressure, CF Cardiac Frequency

Table 2 Data collected during the postoperative period

Postoperative data

Duration of invasive or noninvasive ventilation (hours)

Data on ventilatory monitoring for definition of moderate or severe acute respiratory distress syndrome, according to the Berlin definition [34]

- moderate: $(100 \mathrm{mmHg}<\mathrm{PaO} 2 / \mathrm{FiO} 2 \leq 200 \mathrm{mmHg})$ avec

PEEP $>5 \mathrm{~cm} \mathrm{H} 2 \mathrm{O}$

- severe: $(\mathrm{PaO} 2 / \mathrm{FiO} 2 \leq 100 \mathrm{mmHg})$ avec PEEP $\geq 5 \mathrm{~cm} \mathrm{H} 2 \mathrm{O}$

Arterial blood samples: lactates and blood gas at $\mathrm{H} 1, \mathrm{H} 3$ and daily (D1 to D8)

Venous blood samples: serum creatinine at $\mathrm{H} 3$ and daily from $\mathrm{D} 1$ to D8

Venous blood samples: Troponin on D1, D2

Hourly urine volume output

Duration of hemodialysis, if any

Length of stay in intensive care unit

Length of stay in hospital

Death, if any

H: Postoperative hours, D: Postoperative days

review of eligibility criteria, blood chemistry and serum creatinine, health outcomes assessments.

- Day 0: surgery and randomization - Operative period (Table 1)

- Postoperative period (Table 2)

\section{Statistical methods}

The main objective is to study the potential effectiveness of the IPC regarding postoperative pulmonary and renal complications in the two arms during the first 8 days following surgery. As of other complications may occur before the occurrence of a pulmonary or renal complication, a Cox regression model for competing risks will be used to estimate and test the effect of PCI on the occurrence of a postoperative pulmonary complication [36]. The study will be conducted with an alpha risk of .05 for two-sided tests comparing the null hypothesis to the alternative (the risk of a pulmonary or renal complication differs between the two arms). Both arms will be considered to differ significantly if the null hypothesis is rejected.

\section{Number of patients to be enrolled}

The sample size is calculated taking into account an estimated risk of pulmonary and renal complications around 36\% following OSR for TAAA in patients operated without PCI [6] and a postoperative mortality around $1 \%$ of the patients before the 8 th day (observed in the selected centres). With the hypothesis of a corresponding risk in the PCI group around 15\%, the randomization of 110 patients, with an allocation ratio 
of one to one, will detect a Hazard Ratio $\geq 2.75$ between both arms with a power of $80 \%$ and an alpha risk of $5 \%$.

\section{Discussion}

This project is original since no study has tested PCI as protective against lung and renal damages following OSR for TAAA.

Our hypothesis is that ischemic preconditioning may modulate the inflammatory response associated with visceral ischemia reperfusion caused by the cross clamping of the supra-visceral aorta and thus decrease clinical morbidity, and particularly lung damage. A direct individual benefit is expected with a decrease in mortality and a significant reduction in the total duration of hospitalization and in particular of the days spent in intensive care.

\section{Acknowledgements}

Not applicable.

\section{Declarations}

1-This study is approved by the ethic committee, "Comité Consultatif de Protection des Personnes" (CCPPRB) in France (ref 1867), Identification Number 2018-A00987-48, on October 11, 2018.

\section{Authors' contributions}

Concept of the study: MP, MB, DP. Trial design: MMD, MB, JBR, DP. Surgical procedures: XC, LC, FK, EF, PEM, ED, NC, ES, DP. Manuscript edition: JBR, DP. The author(s) read and approved the final manuscript.

\section{Availability of data and materials}

This study is activated only now. No data are available. Not applicable. The authors have no competing interest to declare.

The study received financial support from the French Clinical Research Program (PHRC 2018).

\section{Consent for publication}

Not applicable.

\section{Author details}

'Department of vascular surgery and Inserm U1096, Rouen University Hospital, 1 rue de Germont, 76031 Rouen Cedex, France. ²Department of Clinical research and Innovation, Rouen University Hospital, Rouen, France. ${ }^{3}$ Department of vascular surgery, Pitié-Salpétrière University Hospital, Paris, France. ${ }^{4}$ Department of vascular surgery, Rangueil University Hospital, Toulouse, France. ${ }^{5}$ Centre Chirurgical Marie Lannelongue, Le Plessis Robinson, France. ${ }^{6}$ Department of vascular surgery, La Timone University Hospital, Marseille, France. ${ }^{7}$ Department of vascular surgery, Pellegrin University Hospital, Bordeaux, France. ${ }^{8}$ Department of vascular surgery, Nouvel Hopital Civil, University of Strasbourg, Strasbourg, France. ${ }^{9}$ Department of vascular surgery, Dijon University Hospital, Dijon, France. ${ }^{10}$ Department of anesthesia, Rouen University Hospital, Rouen, France. ${ }^{11}$ Department of Clinical Research and Innovation, University Hospital, Poitiers, France.

Received: 17 April 2020 Accepted: 19 August 2020

Published online: 27 August 2020

\section{References}

1. Cambria RP, Clouse WD, Davison JK, et al. Thoracoabdominal aneurysm repair : results with 337 operations performed over a 15-year interval. Ann Surg. 2002:236:471-9.

2. Wong DR, Parenti $J$, Green $S Y$, et al. Open repair of thoracoabdominal aortic aneurysm in the modern surgical era : contemporary outcomes in 509 patients. J Am Coll Surg. 2011;212:569-79.
3. Conrad MF, Crawford RS, Davison JK, et al. Thoracoabdominal aneurysm repair : a 20-year perspective. Ann Thorac Surg. 2007;83:S856-61.

4. Coselli JS, LeMaire SA, Preventza O, et al. Outcomes of 3309 thoracoabdominal aortic aneurysm repairs. J Thorac Cardiovasc Surg. 2016; 151:1323-38.

5. Rigberg DA, McGory ML, Zingmond DS, et al. Thirty-day mortality statistics underestimate the risk of repair of thoracoabdominal aortic aneurysm : a statewide expérience. J Vasc Surg. 2006:43:217-22.

6. Estrera AL, Sandhu HK, Charlton-Ouw KM, et al. A quarter century of organ protection in open thoracoabdominal repair. Ann Surg. 2015;262:660-8.

7. Fiane $A E$, Videm $V$, Lingaas PS, et al. Mechanism of complement activation and its role in the inflammatory response after thoracoabdominal aortic aneurysm repair. Circulation. 2003;108:849-56.

8. Feezor RJ, Baker HV, Xiao W, et al. Genomic and proteomic determinants of outcome in patients undergoing thoracoabdominal aortic aneurysm repair. J Immunol. 2004;172:7103-9.

9. Kunihara T, Shiya N, Wakasa S, et al. Assessment of hepatosplanchnic pathophysiology during thoracoabdominal aortic aneurysm repair using visceral perfusion and shunt. Eur J Cardiothorac Surg. 2009:35:677-83.

10. Welborn MB, Oldenburg HS, Hess PJ, et al. The relationship between viscéral ischemia, proinflammatory cytokines, and organ injury in patients undergoing thoracoabdominal aortic aneurysm repair. Crit Care Med. 2000; 28:3191-7.

11. Kalder J, Keschenau P, Hanssen SJ, et al. The impact of selective visceral perfusion on intestinal macrohemodynamics and microhemodynamics in a porcine model of thoracic aortic cross-clamping. J Vasc Surg. 2012 Jul;56(1): 149-58.

12. Hanssen SJ, Derikx JP, Vermeulen, et al. Visceral injury and systemic inflammation in patients undergoing extracorporeal circulation during aortic surgery. Ann Surg. 2008;248:117-25.

13. Hensley K, Robinson KA, Gabbita SP, et al. Reactive oxygen species, cell signaling, and cell injury. Free Radic Biol Med. 2000 May 15;28(10):1456-62.

14. Foulds S, Cheshire NJ, Schachter M, et al. Endotoxin related early neutrophil activation is associated with outcome after thoracoabdominal aortic aneurysm repair. Br J Surg. 1997;84(2):172-7.

15. Galle $C$, De Maertelaer $V$, Motte $S$, et al. Early inflammatory response after élective abdominal aortic aneurysm repair : a comparison between endovascular procédure and conventional surgery. J Vasc Surg. 2000;32: 234-46.

16. Simpson R, Alon R, Kobzik L, et al. Neutrophil and nonneutrophil-mediated injury in intestinal ischemia-reperfusion. Ann Surg. 1993;218(4):444-53 discussion 453-4.

17. Cohen J. The immunopathogenesis of sepsis. Nature. 2002 Dec 19; 420(6917):885-91.

18. Schepens MA, Heijmen RH, Ranschaert W, et al. Thoracoabdominal aortic aneurysm repair : results of conventional open surgery. Eur J Vasc Endovasc Surg. 2009;37:640-5

19. Bellomo R, Ronco C, Kellum JA, et al. Acute renal failure-definition, outcome measures, animal models, fluid therapy and information technology needs: the second international consensus conference of the acute Dialysis quality initiative (ADQI) group. Crit Care. 2004;8:R204-12.

20. Wynn MM, Acher C, Marks E, et al. Postoperative renal failure in thoracoabdominal aortic aneurysm repair with simple cross-clamp technique and $4^{\circ} \mathrm{C}$ renal perfusion. J Vasc Surg. 2015;61:611-22.

21. Tshomba Y, Kahlberg A, Melissano G, et al. Comparison of renal perfusion solutions during thoracoabdominal aortic aneurysm repair. J Vasc Surg. 2014:59:623-33.

22. van Kuijk JP, Flu WJ, Chonchol M, et al. Temporary perioperative decline of renal function is an independent predictor for chronic kidney disease. Clin J Am Soc Nephrol. 2010;5:1198-204.

23. Ali ZA, Callaghan CJ, Lim E, et al. Remote ischemic preconditioning reduces myocardial and renal injury after elective abdominal aortic aneurysm repair : a randomized controlled trial. Circulation. 2007;116(11 Suppl):198-105

24. Walsh SR, Sadat U, Boyle JR, et al. Remote ischemic preconditioning for renal protection during elective open infrarenal abdominal aortic aneurysm repair : randomized controlled trial. Vasc Endovasc Surg. 2010;44:334-40.

25. Murphy N, Vijayan A, Frohlich S, et al. Remote ischemic preconditioning does not affect the incidence of acute kidney injury after elective abdominal aortic aneurysm repair. J Cardiothorac Vasc Anesth. 2014;28: 1285-92. 
26. Li C, Li YS, Xu M, et al. Limb remote ischemic preconditioning for intestinal and pulmonary protection during elective open infrarenal abdominal aortic aneurysm repair: a randomized controlled trial. Anesthesiology. 2013;118: 842-52.

27. De Freitas $S$, Hicks CW, Mouton R, et al. Effects of ischemic preconditioning on abdominal aortic aneurysm repair : a systematic review and metaanalysis. J Surg Res. 2019;235:340-9.

28. Mouton R, Pollock J, Soar J, et al. Remote ischaemic preconditioning versus sham procedure for abdominal aortic aneurysm repair: an external feasibility randomized controlled trial. Trials. 2015;16:377.

29. Twine CP, Ferguson S, Boyle JR. Benefits of remote ischaemic preconditioning in vascular surgery. Eur J Vasc Endovasc Surg. 2014;48:215-9.

30. Garcia S, Rector TS, Zakharova M, et al. Cardiac Remote Ischemic Preconditioning prior to elective vascular surgery (CRIPES) : a prospective, randomized, sham-controlled phase II clinical trial. J Am Heart Assoc. 2016;5: e003916. https://doi.org/10.1161/JAHA.116.003916.

31. Deng QW, Xia ZQ, Qiu YX, et al. Clinical benefits of aortic cross-clamping versus limb remote ischemic preconditioning in coronary artery bypass grafting with cardiopulmonary bypass : a meta-analysis of randomized controlled trials. J Surg Res. 2015;193:52-68.

32. Murry CE, Jennings RB, Reimer KA. Preconditionning with ischemia : a delay of lethal cell injury in ischemic myocardium. Circulation. 1986;74:1124-36.

33. Clavien PA, Selzner $M$, Rüdiger HA, et al. A prospective randomized study in 100 consecutive patients undergoing major liver résection with versus without ischemic preconditioning. Ann Surg. 2003;238:843-50.

34. Ranieri VM, Rubenfeld GD, Thompson BT, et al. Acute respiratory distress syndrome. The Berlin definition. The ARDS definition task force. JAMA. 2012; 307:2526-33.

35. Safi HJ, Miller CC III, Huynh TT, et al. Distal aortic perfusion and cebrospinal fluid drainage for thoracoabdominal and descending thoracic aortic repair : ten years of organ protection. Ann Surg. 2003;238:372-80.

36. Prentice RL, Kalbfleisch JD. Mixed discrete and continuous Cox regression model. Lifetime Data Anal. 2003:9:195-210.

\section{Publisher's Note}

Springer Nature remains neutral with regard to jurisdictional claims in published maps and institutional affiliations.

Ready to submit your research? Choose BMC and benefit from:

- fast, convenient online submission

- thorough peer review by experienced researchers in your field

- rapid publication on acceptance

- support for research data, including large and complex data types

- gold Open Access which fosters wider collaboration and increased citations

- maximum visibility for your research: over $100 \mathrm{M}$ website views per year

At $\mathrm{BMC}$, research is always in progress.

Learn more biomedcentral.com/submissions 